\title{
Quantification of Rehabilitation Success on Mine Site Waste Dumps
}

\author{
S.A. Thompson ATA Environmental, Australia \\ G.G. Thompson Centre for Ecosystem Management, Edith Cowan University, Australia
}

\section{INTRODUCTION}

The Rehabilitation and Degradation Index (RDI) was developed to assesses the extent to which a rehabilitated or disturbed area has progressed toward the creation of a near-natural, self-sustaining, functional ecosystem similar to that in an adjacent undisturbed area or alternatively how a disturbance factor such as agriculture, mining or cane toads have impacted on the functional ecosystems that existed prior to the disturbance.

We argue that the rehabilitation objective for most mine sites and other large-scale disturbance projects should be to restore biotic integrity to a disturbed area. However, biotic integrity is a difficult concept to measure, and so efforts to restore the integrity of a site have often focussed on non-biological measures such as chemical and geophysical parameters (Environmental Protection Authority, 2006; Jasper, 2001; Riley, 1995; Van Horne, 1983). Biotic integrity is defined here as the ability of an ecosystem to support and maintain "a balanced, integrated, adaptive community of organisms having a species composition, diversity and functional organization comparable to that of the natural habitat of the region" (Karr, 1981).

A variety of bio-indicators have been used to assess the impact of a disturbance on the biotic integrity of an area or the effectiveness of a rehabilitation program in restoring the biotic integrity of an area. The rationale that underpins most of these bio-indicators is that environmental disturbance leads to a reduction in the number of species and the dominance of a few species (Patrick, 1949), and a totally degraded or polluted environment supports few or none of the species endemic to the locality.

The RDI is based broadly on the concepts of the Index of Biotic Integrity that was developed by Karr et al. (1986) to measure the health of riverine ecosystems, most of which were degraded by pollution and land management practices. In a rehabilitation context, the Index measures the reverse; i.e. the progress towards the establishment of a near-natural, self-sustaining, functional ecosystem. Others have also used Karr's method and developed similar indices; see Stribbling et al. (1998) for benthic macro-invertebrates, Majer and Beeston (1996) for ants, Bradford et al. (1998) for birds and O'Connell et al. (1998; 2000) for songbirds. Other researchers have used invertebrates (Andersen et al., 2003; Bisevac and Majer, 1998; 1999; Majer, 2001; Nakamura et al., 2003; Read, 1999), birds (Armstrong and Nichols, 2000; Chase et al., 2000; Read and Andersen, 2000), mammals (Fox, 1997; Wilson and Friend, 1999) or reptiles (Nichols and Gardner, 1997; Read, 1999) to measure the integrity of rehabilitated areas. However, many of these studies have only considered the presence of species and not their relative abundance. Thompson and Thompson (2005) provide an argument and rationale for using reptiles as the bio-indicator taxa.

Below we describe the components necessary to calculate a RDI score for a particular site and describe how the RDI can be used to measure the success of a rehabilitation program. We used rehabilitated mine site waste dumps in the Ora Banda region of Western Australia (WA) to develop the index. Three broad quantifiable parameters are used in the RDI; diversity, taxonomic groups and ecological groups.

\section{METHODOLOGY}

We sampled communities of reptiles over five and one half years at five rehabilitated mine site waste dumps (Gimlet, Golden Arrow, Palace, Rose and Wendy Gully) and the adjacent undisturbed areas, plus another five undisturbed areas (Salmon Gums, Spinifex, Davyhurst, Security and Crossroads) in the gold mining region of Ora Banda ( $30^{\circ} 27^{\prime} \mathrm{S}, 121^{\circ} 4^{\prime} \mathrm{E}$; approximately $50 \mathrm{~km}$ north of Kalgoorlie, WA). Rehabilitation had been in place at the commencement of this project (June 2000) at Wendy Gully for 3 years, Palace for 4 
years, Rose for 7 years, and Gimlet for 8 years. At Golden Arrow there was a two-stage program, with rehabilitation on the top of the waste dump having been there for 5 years and on the sides for 9 years. Natural sites that were only separated from the waste dump by a vehicle track were used as undisturbed sites for comparative purposes. Five undisturbed sites not adjacent to a waste dump were also included in our analysis of; (a) the maximum practical Index score, and (b) a target score (see below). When comparison was made between rehabilitated areas and undisturbed areas, only those undisturbed areas that were adjacent to rehabilitated areas were used.

All sites other than Golden Arrow were pit-trapped on thirteen occasions between September 2000 and January 2006 (September and December in 2000; January, April, June, September and December in 2001; January, April and June in 2002; January 2003, 2004 and 2006) using alternating 20 L PVC buckets and 150 $\mathrm{mm}$ PVC pipes (600 mm deep) joined by $250 \mathrm{~mm}$ high x $30 \mathrm{~m}$ long fly-wire drift fences. Golden Arrow was added to the survey program in September 2001 and was included in all subsequent surveys. Each undisturbed site had eight rows of six pit-trap lines that were joined by a drift fence. On waste dumps there were six lines of pit-traps on the side of each waste dump and six lines on the top of each waste dump. Traps on waste dumps and the adjacent undisturbed area would have each sampled reptiles with a 1-4 ha. All pittraps were dug in during June-July 2000 (except Golden Arrow which was dug in during June 2001) to minimise potential digging-in effects on reptile capture rates. For the surveys from September 2000 until January 2003, each pit-trap was opened for seven days and pit-traps were cleared daily. For the January 2004 and 2006 surveys, six funnel traps $(800 \times 200 \times 200 \mathrm{~mm}$, with a funnel at each end) were placed along each drift fence and all traps were left open for 14 days to increase the survey effort as it became evident that a high trapping effort was important to obtain robust RDI scores. This change in method did not affect the development of the RDI that we outline below. Reptiles were identified before immediately being released adjacent to their point of capture.

The RDI was developed using trapping data collected between September 2000 and June 2002. We used data collected over five January survey periods (i.e. 2001 to 2004 and 2006) to assess changes in rehabilitation.

\section{$3 \quad$ RESULTS}

Fox (1982) and Fox and Fox (1984) reported that densities for early colonising species were higher in the early stages of succession than when the ecosystem had matured. Therefore, our RDI is structured to measure deviation for each parameter from the undisturbed value, be it lower or higher. If the waste dump had the same reptile assemblage as the adjacent undisturbed area, then each site would contribute $50 \%$ of the total captures for the combined area, both sites would have the same diversity and evenness scores for the same trapping effort, and they would have a similarity score of 1 . The greater the deviation between the rehabilitated and adjacent undisturbed area, the less the rehabilitated area resembled the adjacent undisturbed area. In the RDI this deviation is converted to a percentage. The relative difference between the rehabilitated site and the adjacent undisturbed area for each sub-parameter shows the extent to which the rehabilitated site is similar to (or deviated from) the adjacent undisturbed area. The generic formula used to calculate the difference between a rehabilitated site and adjacent undisturbed area for each sub-parameter as a percentage is:

$$
\text { Relative score }=100-\left(2 \times\left(\operatorname{ABS}\left(50-\left(\frac{\text { rehab }}{\text { undist }+ \text { rehab }}\right) \times 100\right)\right)\right)
$$

Where rehab $=$ sub-parameter score for the rehabilitation site (i.e. evenness, $\log$ series diversity or $\mathrm{S}_{\mathrm{R}}$ score), undist $=$ score for the undisturbed area (i.e. evenness, Log series diversity or species richness score), and $\mathrm{ABS}=$ absolute values (all values are converted to a positive).

The Index provides a score out of 100 to indicate the extent to which the reptile assemblage on a rehabilitated area resembles that in the adjacent undisturbed area. A score of zero represents a totally degraded ecosystem and a score of 100 a near-natural, self-sustaining, functional ecosystem, equivalent to that in the adjacent undisturbed area. 


\subsection{Diversity Parameter}

The diversity parameter consists of four sub-parameters.

\subsubsection{Species richness}

Species richness $(\mathrm{S})$ is the number of species present in any particular area. It is easily compared among sites and is an important characteristic of any community, however, absolute species richness is rarely if ever known for a faunal community (Gotelli and Graves, 1996; Rodda et al., 2001) and it is generally inappropriate to compare species counts from two communities that were not censused exhaustively and identically. Species richness calculated from rarefaction curves $\left(S_{R}\right)$ was therefore used to compare species richness between the disturbed (with a smaller sample size) and undisturbed (with a larger sample size) areas. Rarefaction calculates the expected number of species in a data set adjusted for sample size, thus enabling us to compare species richness for two sites (e.g. rehabilitated area and the adjacent undisturbed area) when a different number of individuals were caught on the two sites (Gotelli and Graves, 1996). These data were rarefied using EcoSim Software (Gotelli and Entsminger, 2001) and a Beta-P non-linear regression model was used to calculate a curved line of best fit through the data (Thompson et al., 2003). This relative species richness score for the waste dump and the undisturbed area were then inserted in equation 1 to calculate a relative species richness score.

\subsubsection{Log series diversity}

Log series diversity was used to compare the diversity in rehabilitated sites with the adjacent undisturbed areas because it has good discriminating ability, has low sensitivity to sample size and is simple to calculate (Kempton and Taylor, 1974; Magurran, 1988). The relative score for the waste dump compared with the adjacent undisturbed area for Log series diversity was calculated using equation 1.

\subsubsection{Similarity}

Morisita-Horn similarity scores were used to compare the similarity of reptile assemblages between waste dumps and adjacent undisturbed areas. The Morisita-Horn similarity index is a quantitative similarity index (Magurran, 1988) and was selected because it is not strongly influenced by species richness or sample size (Wolda, 1981), and was recommended by Magurran (1988).

\subsubsection{Evenness}

Evenness (E) of a population was used as another measure of diversity since it describes the extent to which individuals are equally partitioned among all species. If the evenness score for a site is 1 , then each species makes up an equal proportion of the assemblage (i.e. equal abundance of each species). The score for the waste dump compared with the adjacent undisturbed area for evenness is then calculated using equation 1.

\subsubsection{Weighting of scores}

Equal weightings (25\%) were applied to each of the four sub-parameters then added to calculate a score out of 100 for the diversity parameter.

\subsection{Taxonomic Parameter}

The taxonomic parameter compares the number of individuals in each taxa (e.g. the number of agamids, geckos, pygopods, skinks, varanids, scolecophidians and elapids found on a waste dump and the adjacent undisturbed area). Each of these taxonomic groups was considered a sub-parameter of the taxonomic parameter. If the relative abundance for each taxonomic group was similar for a waste dump and the adjacent undisturbed area, then the waste dump could be considered approaching an advanced stage in the development of an ecosystem similar to the adjacent undisturbed area for the taxonomic parameter. The relative score for the waste dump compared with that in the adjacent undisturbed area for each taxonomic group was then calculated using equation 1 . 
Different weightings are applied to each of these sub-parameters based on the relative proportion that each taxonomic group represents in the undisturbed area. For example, if $5 \%$ of all reptiles captured on the undisturbed area were agamids, then agamids would be weighted as $5 \%$ of the total.

\subsection{Ecological Parameter}

The ecological parameter compares how reptile assemblages on rehabilitated areas and the adjacent undisturbed areas are segregated into various niches. The niche structure for an assemblage of reptiles can be partitioned in at least three basic ways; temporally, spatially and trophically. If the ecological groups were similarly proportioned for the waste dump and the adjacent undisturbed area, then the waste dump could be considered approaching an advanced stage in the development of an ecosystem similar to that in the adjacent undisturbed area for the ecological parameter.

The ecological sub-parameters are dietary preference, dietary specialists, habitat preference, predatory strategy and activity period. Each sub-parameter is further divided into categories (dietary preference predominantly omnivore, predominantly vertebrate carnivore, and predominantly invertivore; habitat preference - predominantly terrestrial, predominantly arboreal and predominantly fossorial; predatory strategy - predominantly sit-and-wait, predominantly actively foraging and predominantly widely foraging; activity period - predominantly nocturnal and predominantly diurnal). We defined an active-foraging species as a species that forages over a large search area looking for dispersed food sources (e.g. Varanus gouldii). A widely-foraging reptile was defined as a species that forages for a concentrated food source and then stays at the site of this food source for a period of time (e.g. Moloch horridus eating ants). A sit-and-wait predator does not move around searching for prey but waits in ambush for its prey to come past. Categories selected for each species are based on a search of the literature, our on-site observations and personal communication with an expert panel. Often multiple preferences are presented in the literature, some of which may reflect geographic variation. In these circumstances we chose the most common or took advice from an expert panel. Species are assigned to a category in each sub-parameter based on adult species behaviour. It is acknowledged that some of these categories are somewhat artificial as there is likely to be an overlap as some species will fit into more than one category; for example, see Perry (1999) for discussion on predatory strategies.

The relative score for the waste dump compared with the adjacent undisturbed area for each category was calculated using equation 1. Each sub-parameter was given an equal weighting, as was each category score within each sub-parameter. These weighted scores were summed to provide the ecological parameter score for the waste dump.

\subsection{Parameter Weightings and RDI Calculations}

The diversity, taxonomic and ecological parameters were weighted differently to calculate the final RDI score. The weights were determined so that the RDI score had minimum variance for 'identical' undisturbed sites. The weightings for diversity, taxonomic and ecological parameters were calculated by comparing two 'near identical' sites. 'Near identical' sites were obtained by sub-sampling each of the 10 undisturbed areas surveyed at Ora Banda for the first 10 survey periods. Captures from each undisturbed area were divided into two sub-areas (lines 1, 3, 5, 7, i.e. odd pit-lines; and lines 2, 4, 6, 8, i.e. even pit-lines) for the first 10 survey periods. Sub-sampling from the same pit-trapping grid was considered as similar as any two data sets could be in the Ora Banda area (i.e. we presumed that the areas sampled were homogenous habitats and the two sub-areas sampled contained identical reptile assemblages).

A minimum variance model between the overall scores for the 20 sub-sampled undisturbed areas was used to calculate the most appropriate weightings for each parameter. An RDI score was calculated for each subsampled undisturbed area (i.e. odds $v s$ evens, and evens $v s$ odds; $\mathrm{n}=20$ ) for all possible combinations (i.e. 4851) of different weightings for each of the three parameters (i.e. weightings of $1,1,98 ; 1,2,97 ; 1,3,96$, etc) for the 20 sub-sampled undisturbed areas. These were ranked and the mean weightings for the 50 combinations with lowest variance were calculated. The mean weightings that resulted in the minimum variance for the sub-sampled undisturbed areas were 32 for the diversity parameter, 43 for the taxonomic parameter, and 25 for the ecological parameter. These weightings when multiplied by the parameter score 
optimised the RDI score for the rehabilitated site. These weightings have been used in all calculations of RDI scores.

\subsection{Target RDI Score}

A score of 100 for a rehabilitated waste dump, although ideal, is unlikely. Even if the faunal assemblage on the waste dump was a perfect replica of the adjacent undisturbed area, pit-trapping data for the two sites are unlikely to be identical due to sampling error, and a range of other variables. As a consequence, a target score of 100 for a waste dump is an unreasonable expectation. Complete rehabilitation of a waste dump is likely to take many years, possibly decades or even longer. The ultimate goal is to identify when land managers can be relieved of their environmental obligations to sites, knowing that with time and natural processes, the rehabilitated areas will eventually become near-natural, self-sustaining, functional ecosystems similar to that in adjacent undisturbed areas. This is a judgement decision, and science can only provide the information to be used as a basis for making this judgement. We have therefore provided a practical target RDI score for a rehabilitated area, that represents a level that when achieved requires no further intervention by land managers and the waste dump will continue to progress towards a functional ecosystem similar to that in the adjacent undisturbed area.

To develop a target score, each of the 10 undisturbed habitats were sub-divided into two sampling areas. One was called the 'undisturbed area' and the other the 'rehabilitation area', and RDI scores were calculated for each. The designation of each of the two sampling areas was then reversed and RDI scores calculated for the other 10 sites, providing RDI scores for 20 sites compared with their 'identical' neighbour. These are the maximum scores likely to be achieved with the sampling effort we employed.

The mean RDI score for the 20 'rehabilitation sites' was $86.5 \pm$ se 0.91 . This suggests that when an undisturbed area was sub-sampled the highest rehabilitation score that could be achieved was approximately 86.5, reflecting sampling variability and a minor lack of homogeneity among sites so an appropriate target rehabilitation score for practical purposes is about 86. The decision as to how far below this score is 'reasonable', is an arbitrary judgement, however, government regulators will require such a score if they are to use the RDI. Based on an assessment of the Ecosystem Function Analysis (Tongway, 2001) scores for four waste dumps and a detailed knowledge of their reptile assemblages, it is suggested that the target score might be 10 standard errors below the mean of 86.5 (i.e. 77.5). A similar target score could be calculated as two standard deviations below the mean score (i.e. limit 78.5) or a distance below the mean score equivalent to the distance above to reach 100 (i.e. $100-86.5=13.5 ; 86.5-13.5=73$ ). These are likely to be 'high' target scores and continued refinement of the RDI will assist in assessing whether the target score needs to be adjusted.

\subsection{Sample Size, Hatchlings and Temporal Variations}

Calculated RDI scores are influenced by seasonal and year-to-year variations in weather patterns and the consequential changes in the reptile assemblage. During years with minimal rainfall numbers for some species are reduced, others are increased. Given the assemblage structure on waste dumps and undisturbed areas differs, then this affects the RDI scores.

In all reptile assemblages a proportion of the species will be caught in low numbers and are considered to be 'rare'. The inclusion of 'rare' species in the dataset has a minimal influence on the calculated RDIO score, provided the sampling effort is reasonable. Small field sample sizes reduce significantly the robustness of the RDI scores and results in appreciable variation in scores. Sample sizes for the combined rehabilitation and undisturbed areas ideally should be around 250 individuals for each survey period. However, a lower number will be appropriate for areas in an early stage of rehabilitation as reptile numbers will generally be much lower than the undisturbed areas.

\section{DISCUSSION}

The RDI score provides a quantitative representation of the progress that the ecosystem on a rehabilitated site has made toward resembling that in the adjacent undisturbed area, using the reptile assemblage as a 
proxy to compare the biotic integrity of both areas. RDI scores will increase as the reptile assemblage in the rehabilitated area approaches that of the adjacent undisturbed area.

A waste dump is devoid of vegetation and fauna when it is created. An appropriately constructed and vegetated waste dump should then move through various succession stages as the rehabilitation matures, to eventually achieve the final objective (Appendix 1). A completely disturbed area (e.g. newly constructed waste dump) that is devoid of reptiles will have a score of zero. The score will increase towards 100 as the reptile assemblage on the waste dump converges with that in the adjacent undisturbed area. The attributes for each of the stages in this progression are described in Appendix 1. These are not discrete stages, but are a continuum of rehabilitation progress. If a waste dump can reach the target score, then it is expected that given time the waste dump will continue to progress towards a functional ecosystem similar to that in the adjacent undisturbed area.

\subsection{Changes Over Time}

Table 2 indicates the RDI scores for five waste dumps at Ora Banda calculated from data collected during January surveys. There is considerable variability in the RDI scores for January 2001 to 2003 . This is mostly due to two factors; a) small samples of reptiles being caught during these surveys, and b) substantial changes in the vegetation and vegetation condition in the Ora Banda region over the three years. Substantial rain in early 2000 resulted in good plant growth and flowering in autumn that year, which in turn increased the number of hatchlings caught in the January 2001 survey. In contrast, vegetation was in relatively poor condition in January 2003, the year with the greatest variability in results. The survey effort was quadrupled for surveys in January 2004 and 2006, and these RDI scores represent a robust indication of reptile assemblages on waste dumps compared with the adjacent undisturbed areas.

Table 2 RDI scores for five waste dumps calculated from data collected during surveys in January

\begin{tabular}{lccccc}
\hline Waste dumps & $\begin{array}{c}\text { Wendy } \\
\text { Gully }\end{array}$ & Rose & Palace & $\begin{array}{c}\text { Gimlet } \\
\text { South }\end{array}$ & $\begin{array}{c}\text { Golden } \\
\text { Arrow }\end{array}$ \\
\hline January 2001 & 31.7 & 51.2 & 38.5 & 39.5 & - \\
January 2002 & 54.3 & 59.8 & 36.1 & 38.2 & 51.1 \\
January 2003 & 71.0 & 36.0 & 25.0 & 51.8 & 49.7 \\
January 2004 & 44.2 & 68.6 & 52.6 & 49.7 & 51.3 \\
January 2006 & 57.9 & 65.2 & 76.8 & 49.3 & 58.3 \\
\hline
\end{tabular}

\subsection{RDI in Other Habitat Types}

One of the criteria for assessing the robustness of the RDI is its applicability over a range of habitats. There is a paucity of data in the literature on reptile assemblages that have been systematically surveyed in rehabilitated areas and adjacent undisturbed areas over a period of years or even one year. We calculated RDI scores for data from two other Australian sites and a wet-dry tropical site on Misima Island east of Papua New Guinea. Diets, habitat preference, predatory strategy and activity period for reptiles and amphibians captured in these surveys were collected from the literature, from personal communication with field ecologists and biologists and/or personal observations. 


\subsubsection{Mount Whaleback, WA}

Walker et al. (1986) reported a survey of the Mount Whaleback waste dump at Mount Newman between March 1984 and January 1986. The recaptures and unidentified reptiles were excluded from the calculation of the RDI score. Mount Whaleback had a RDI score of 45. These data show that nine years after rehabilitating the area, the reptile assemblage was still appreciably different to the adjacent undisturbed site. The RDI score was similar to the waste dumps around Ora Banda with a similar period of rehabilitation, although the habitat was very different (mostly spinifex). Walker et al. (1986) made no overall comment about the success of the rehabilitation on Mount Whaleback waste dump, but did say that almost half of the regionally present terrestrial vertebrates were caught, despite having only minor remnants of vegetation and a steep unvegetated slope.

\subsubsection{Cobar, NSW}

Halliger (1993) investigated the development of two rehabilitated mine sites near Cobar, New South Wales and compared them to an adjacent unmined site. One area was mined until 1919, and the other around 1952. Although not explicitly stated, it is implied that no planned rehabilitation was undertaken at either of the mine sites and the vegetation and fauna present were due to natural processes. The area that had not been mined since 1919 had a RDI score of 70.7 and the area not mined since 1952 had a score of 51.6. Although the species richness was lower than at Ora Banda and there were fewer reptiles captured, the RDI score showed that the older rehabilitated site more closely resembled the nearby analogue undisturbed area.

\subsubsection{Misima, PNG}

The RDI was applied to three rehabilitated areas associated with the Misima mine site and an adjacent rainforest site. These areas had been rehabilitated for 20 months, 5 years and 9-10 years at the time of the assessment. Reptiles and frogs were incorporated into the calculations of RDI scores. The comparison between these three sites and rainforest indicates that there is a clear progression in the development of the rehabilitated sites from the site rehabilitated 20 months ago $(\mathrm{RDI}=38.3)$, to the site rehabilitated 5 years ago $(\mathrm{RDI}=43.1)$ to the site rehabilitated 9-10 years ago $(\mathrm{RDI}=54.4)$. These three waste dumps all have low scores for the ecological parameter. This is often the case for emerging ecosystems, as a range of niches for particular species are not available during the early stages of the rehabilitation process. It might also be expected that the relatively rare species, with particular niche requirements, would be slow to colonise the rehabilitated sites and this will significantly reduce the ecological parameter score.

This is a particularly good example as it demonstrates the progression in RDI scores as the rehabilitation progresses, and indicates that the RDI is a useful tool in semi-arid and the wet-dry tropical habitats, and that amphibians can be incorporated into the calculations.

\subsection{RDI as a Degradation Index}

The RDI is calculated by comparing the reptile assemblage on one site with another. For rehabilitated degraded areas, the ecosystem is progressing through numerous succession stages and RDI scores should progressively increase as the reptile assemblage in the rehabilitated area moves closer to mimicking that in the adjacent undisturbed area. The reverse is the situation for an area where the ecosystem is being impacted on by a disturbance variable such as pollution, feral animals or weed invasion. The RDI can be used to compare a 'control' site with one that is progressively being degraded. It is therefore a useful tool in quantifying rehabilitation success and degradation of habitats if appropriate analogue sites are available.

\section{CONCLUSION}

The RDI provides an objective, relatively simple and easy to use tool that can be used to measure both the success of a rehabilitation program in restoring the biotic integrity to a degraded area or the impact of a disturbance on a functioning ecosystem. If the reptile assemblage is a useful proxy of the development of the functional ecosystem for a rehabilitated site when compared with the adjacent undisturbed area, then this score can be used by land managers as a measure of rehabilitation success. As the RDI only monitors the assemblage structure of reptiles, it needs to be considered in conjunction with other measures or indices of 
stability (e.g. Landscape Function Analysis; Tongway, 2001), vegetation structure and early species colonisation (e.g. invertebrates) to provide an overall assessment of ecosystem function.

\section{ACKNOWLEDGEMENTS}

This research was undertaken with ethics approval granted by Edith Cowan University and licences issued by the Department of Conservation and Land Management. This research was financially supported by OMG Cawse Nickel, Placer Dome Asia Pacific, Kalgoorlie West Operations and Misima Mines Ltd for which we are very appreciative.

\section{More information}

We have presented a succinct summary of how the RDI is calculated and can be used. More detailed information on the calculations, sampling and how the Index can be used are available by emailing either of the authors.

\section{REFERENCES}

Andersen, A.N., Hoffmann, B.D. and Somes, J. (2003) Ants as indicators of minesite restoration: community recovery at one of eight rehabilitation sites in central Queensland. Ecological Management and Restoration 4 Supplement, S12-19.

Armstrong, K.N. and Nichols, O.G. (2000) Long-term trends in avifaunal recolonisation of rehabilitated bauxite mines in the jarrah forest of south-western Australia. Forest Ecology and Management 126, pp. 213-225.

Bisevac, L. and Majer, J.D. (1998) Invertebrates as success indicators for mine site rehabilitation. Fauna habitat reconstruction after mining, 10-11 October 1997, Asher, C.J. and Bell, L.C. (eds), Australian Centre for Mining Environmental Research, Melbourne.

Bisevac, L. and Majer, J.D. (1999) An evaluation of invertebrates for use as success indicators for minesite rehabilitation. The other 99\%: The conservation and biodiversity of invertebrates. Ponder, W.F. and Lunney, D. (eds). Transactions of the Royal Zoological Society of New South Wales. Sydney, pp. 46-49.

Bradford, D.F., Franson, S.E., Neale, A.C., Heggem, D.T., Miller, G.R. and Canterbury, G.E. (1998) Bird species assemblages as indicators of biological integrity in Great Basin Rangeland. Environmental Monitoring and Assessment 49, pp. 1-22.

Chase, M.K., Kristan, W.B., Lynam, A.J., Price, M.V. and Rotenberry, J.T. (2000) Single species as indicators of species richness and composition in California coastal sage scrub birds and small mammals. Conservation Biology 14(2), pp. 474-487.

Environmental Protection Authority (2006) Guidance for assessment of environmental factors: Rehabilitation of terrestrial ecosystems, No 6. Environmental Protection Authority, Perth.

Fox, B.J. (1982) Fire and mammalian secondary succession in an Australian coastal heath. Ecology 63(5), pp. 13321341.

Fox, B.J. and Fox, M.D. (1984) Small-mammal recolonisation of open-forest following sand mining. Australian Journal of Ecology 9, pp. 241-252.

Fox, J.E.D. (1997) Fauna habitat reconstruction after mining. Fauna habitat reconstruction after mining, 10-11 October 1997, Asher, C.J. and Bell, L.C. (eds) Australian Centre for Mining Environmental Research, Adelaide, pp. 151160.

Gotelli, N.J. and Entsminger, G.L. (2001) Swap and fill algorithms in null model analysis: rethinking the knight's tour. Oecologia 129, pp. 281-291.

Gotelli, N.J. and Graves, G.R. (1996) Null models in ecology. Smithsonian Institution Press, Washington.

Halliger, M. (1993) Reptiles on regenerating mine sites in western New South Wales. Herpetology in Australia: a diverse discipline, Lunney, D. and Ayers, D. (eds), Royal Zoological Society of New South Wales, New South Wales, pp. 327-332.

Jasper, D. (2001) Soil indicators and monitoring of rehabilitation, Centre for Land Rehabilitation, Perth.

Karr, J.R. (1981) Assessment of biotic integrity using fish communities. Fisheries 6, pp. 21-27. 
Karr, J.R., Fausch, F.D., Angermeiser, P.L., Yant, P.R. and Schlosser, I.J. (1986) Assessing biological integrity in running waters: a method and its rationale. Illinois Natural History Survey Special Publication 5, Illinois.

Kempton, R.A. and Taylor, L.R. (1974) Log-series and log-normal parameters as diversity discriminants for the Lepidoptera. Journal of Animal Ecology 43, pp. 381-399.

Magurran, A.E. (1988) Ecological diversity and its measurement., Princeton University Press, Princeton, New Jersey.

Majer, J.D. (2001) Invertebrates as indicators, Centre for Land Rehabilitation, Perth.

Majer, J.D. and Beeston, G. (1996) The biodiversity integrity index: an illustration using ants in Western Australia. Conservation Biology 10(1), pp. 65-73.

Nakamura, A., Proctor, H. and Catterall, C.P. (2003) Using soil and litter arthropods to assess the state of rainforest restoration. Ecological Management and Restoration 4 (Supplement), pp. S20-28.

Nichols, O.G. and Gardner, J.H. (1997) Long-term monitoring of fauna return in bauxite-mined areas of the Darling Range, Proceedings of the workshop on fauna habitat reconstruction after mining, C.J. Asher, and L.C. Bell (eds). Australian Centre for Mining Environmental Research, Adelaide, pp. 99-109.

O'Connell, T.J., Jackson, L.E. and Brooks, R.P. (1998) The bird community index: A tool for assessing biotic integrity in the Mid-Atlantic Highlands, Pennsylvania State University, University Park, Pennsylvania.

O'Connell, T.J., Jackson, L.E. and Brooks, R.P. (2000) Bird guilds as indicators of ecological condition in the central Appalachians. Ecological Applications 10(6), pp. 1706-1721.

Patrick, R. (1949) A proposed biological measure of stream conditions based on a survey of Conestoga Basin, Lancaster County, Pennsylvania. Proceedings of the Academy of Natural Science 101, pp. 277-295.

Perry, G. (1999) The evolution of search modes: ecological versus phylogenetic perspectives. American Naturalist 153(1), pp. 98-109.

Read, J.L. (1999) Birds, reptiles and ants as indicators of ecological impacts of mining and pastoralism at Olympic Dam in the Australian arid zone. Unpublished PhD Thesis, University of New England, Armidale, NSW.

Read, J.L. and Andersen, A.N. (2000) The value of ants as early warning bioindicators: responses to pulsed cattle grazing at an Australian arid zone locality. Journal of Arid Environments 45, pp. 231-251.

Riley, S.J. (1995) Mine rehabilitation: can we know the future? A geomorphological perspective from Australia. Physical Geography 16(5), pp. 402-418.

Rodda, G.H., Campbell, E.W. and Fritts, T.H. (2001) A high validity census technique for herpetofaunal assemblages. Herpetological Review 32(1), pp. 24-30.

Stribbling, J.B., Jessup, B.K. and White, J.S. (1998) Development of a benthic index of biotic integrity for Maryland streams. Annapolis. Maryland Department of Natural Resources, Report No. CBWP-EA-98-3.

Thompson, G.G. and Thompson, S.A. (2005) Mammals or reptiles, as surveyed by pit-traps, as bio-indicators of rehabilitation success for mine sites in the goldfields of Western Australia? Pacific Conservation Biology, 11, pp. 268-286.

Thompson, G.G., Withers, P.C., Pianka, E.R. and Thompson, S.A. (2003) Assessing biodiversity with species accumulation curves; inventories of small reptiles by pit-trapping in Western Australia. Austral Ecology 28, pp. 361-383.

Tongway, D. (2001) Assessing rehabilitation success: A training course to understand, assess and monitor the success of mine rehabilitation using ecosystem function analysis indicators. CSIRO, Canberra.

Van Horne, B. (1983) Density as a misleading indicator of habitat quality. Journal of Wildlife Management 47(4), pp. 893-901.

Walker, K.J., Osborne, J.M. and Dunlop, N. (1986) Vertebrate colonisation after revegetation of a rehabilitated iron ore waste dump, Newman, W.A. Environmental Workshop, 1986 Papers, Australian Mining Industry Council, Launceston, pp. 113-150.

Wilson, B.A. and Friend, G.R. (1999) Responses of Australian mammals to disturbance: A review. Australian Mammalogy 21, pp. 87-105.

Wolda, H. (1981) Similarity indices, sample size and diversity. Oecologia 50, pp. 296-302. 

and Degradation Index score

\begin{tabular}{|c|c|}
\hline Attributes & Index score \\
\hline $\begin{array}{l}\text { Comparable to the best situation without human impact; } \\
\text { regionally expected species for habitat type; species } \\
\text { present with a full array of age (size) classes; balanced } \\
\text { ecological structure; self-sustaining functional } \\
\text { ecosystem. }\end{array}$ & $86-100$ \\
\hline $\begin{array}{l}\text { Species richness approaching expected levels; not all } \\
\text { late succession species present, some species present } \\
\text { with less optimal abundances or size distributions; } \\
\text { ecological structure incomplete. }\end{array}$ & $61-85$ \\
\hline $\begin{array}{l}\text { Species richness below that in the undisturbed area, } \\
\text { some groups not well represented, some specialists not } \\
\text { present. }\end{array}$ & $41-60$ \\
\hline $\begin{array}{l}\text { Lack of specialists, fewer species than in the undisturbed } \\
\text { area, skewed ecological structure and relative } \\
\text { abundances. }\end{array}$ & $21-40$ \\
\hline $\begin{array}{l}\text { Few vertebrates present; only early colonisers present, } \\
\text { lack of community structure. }\end{array}$ & $11-20$ \\
\hline $\begin{array}{l}\text { Only opportunistic early colonisers are present. No } \\
\text { community structure. }\end{array}$ & $0-10$ \\
\hline No reptiles present. & 0 \\
\hline
\end{tabular}

